\title{
Metapsicologia das fronteiras, recusa da realidade e clivagem - aspectos da clínica atual ${ }^{19}$
}

\section{José Martins Canelas Netoº}

O tema da clínica em movimento, assim como o do movimento na clínica, me levou a percorrer mais uma vez a obra de Freud e dos autores com os quais mais me identifico em minhas reflexões. A clínica em movimento remete ao que vou chamar de clínica atual. Esta comporta uma diversidade complexa de patologias, as quais se distinguem das neuroses e também das psicoses: patologias narcísicas, psicossomáticas, distúrbios do comportamento alimentar, psicopatias, toxicomanias, casos-limite ou fronteiriços ou borderline, normopatias, etc. Esse amplo leque de organizações psíquicas nos coloca desafios, porque temos de lidar com os limites de nossa prática analítica e com a questão da analisabilidade de certos pacientes, o que nos obriga a questionar nossas concepções e o manejo do enquadre analítico.

Diante da grandeza da obra de Freud e após sua morte, autores renomados desenvolveram suas ideias em diferentes direções, tendo levado a uma fragmentação teórica importante e a um distanciamento da metapsicologia freudiana. Com o que chamou de retorno a Freud, Jacques Lacan, na psicanálise francesa, teve um papel fundamental ao retomar a obra freudiana numa leitura crítica mais moderna. E, mais recentemente, no final do século XX, André Green, Jean Laplanche, J.-B. Pontalis e outros analistas franceses aprofundaram a reflexão baseada na metapsicologia freudiana, a qual a meu ver passou a ser o fundamento da teorização psicanalítica. Sinto-me identificado com esse caminho. Proponho neste texto retomar o caminho de Freud, sobretudo após a virada dos anos 1920, tentando correlacionar suas ideias com a clínica atual.

A reflexão de Freud diante dos fracassos da análise e da reação terapêutica negativa marca a mudança em suas hipóteses metapsicológicas a partir de 1920. Um dos pontos que mudaram foi a colocação à distância do inconsciente fundado no conceito de representação. No artigo de 1926 "Psicanálise", afirma que na origem todas as forças psíquicas são de natureza pulsional. Em 1923, em O Ego e

\footnotetext{
19 Trabalho apresentado na plenária "A clínica em movimento" no II Simpósio Bienal SBPSP "Fronteiras da Psicanálise: a clínica em movimento", no dia 21 de agosto de 2020.

${ }^{20}$ Analista didata da SBPSP, psiquiatra pela Universidade de Paris, França.
} 
o Id, capítulo 1, observa que o inconsciente não coincide com o recalcado, que uma parte importante do Ego é inconsciente e também que a representação está ausente do Id, situando-se no Ego, consciente ou inconsciente. Em 1933, nas Novas conferências introdutórias à psicanálise, conferência 31, "A dissecção da personalidade psíquica", ele insiste não sobre as representações, mas sobre a relação com o soma, com as necessidades pulsionais, a energética e o ponto de vista econômico, dando claramente prevalência à ideia de movimento com a noção de moção pulsional. ${ }^{21} \mathrm{~A}$ representação, nesse movimento do pensamento de Freud, é considerada atividade do Ego, num grau de priorização mais elevado. Além disso, ele acrescenta a essa visão o papel do mundo externo, do objeto. $\mathrm{O}$ trabalho do pensamento (perlaboração) ocorre entre o Id (mundo interno) e a ação (dentro do mundo externo). Penso que aqui já se apresenta a ideia de uma primeira fronteira da psique entre interno e externo, dentro e fora.

Outro ponto a acrescentar sobre a metapsicologia de Freud nesse período final de sua obra é a importância central dada ao conceito de pulsão. A pulsão é a matéria-prima do psiquismo primordial. As pulsões de vida e de morte com suas intricações e desintricações constituem esse psiquismo elementar. A pulsão se enraíza profundamente no somático; já a psique depende da demanda endereçada ao outro.

O papel do objeto nessa concepção de Freud é o de revelar a pulsão. Pulsão e objeto constituem um par fundamental na reflexão freudiana. Quando intervém a pulsão de morte, podemos falar em função desobjetalizante, a qual impede a aquisição de objetos psíquicos.

Após essa brevíssima síntese de algumas ideias de Freud, penso ser importante colocar a questão: o limite/fronteira poderia ser um conceito metapsicológico?

Comecemos nos perguntando: o que é o limite/fronteira de alguém? O que vem em primeiro lugar à mente é a ideia do envelope da pele, um continente. Mas este apresenta várias soluções de continuidade, isto é, buracos. Nosso continentepele apresenta-se descontínuo, com buracos, que desempenham um papel de portas, passagens: olhos, orelhas, nariz, boca, ânus, órgãos genitais. Zonas erógenas que funcionam nos dois sentidos: para dentro e para fora. Uma

21 Tradução a partir da versão francesa, correspondente a investimentos instituais na de Paulo César de Souza. 
concepção figurada pode nos servir como modelo para um Eu inicial: por um lado, a superfície contínua da pele, a qual delimita claramente um dentro e um fora; por outro, as soluções de continuidade, que constituem os buracos das zonas erógenas, zonas de passagem entre dentro e fora.

Em "Neurose e psicose" (1924/2011b), ao se perguntar sobre o mecanismo correspondente na psicose ao recalcamento da neurose, Freud avança a hipótese de que haveria na psicose uma retirada do investimento que tinha sido colocado para fora pelo Ego. Essa retirada do investimento do fora é a pré-figuração da clivagem do Ego, que vai ser abordada no final da vida por Freud, no artigo inacabado de 1938. Esse conceito é um dos pilares da metapsicologia dos casos fronteiriços, por exemplo. Antes dele, o conceito de recusa - Verleugnung (denegação, negação ou repúdio da realidade) corresponderia a um recalque da percepção da realidade externa. Examinarei mais à frente estes dois conceitos: Verleugnung e clivagem.

No artigo "A negação" (1925/1987), Freud traz a noção de um limite originário constituído pela operação inaugural do julgamento de existência. Ele considera que, antes do surgimento do objeto, surgiria a oposição subjetivo/objetivo:

Originalmente, então, a existência da representação já é uma garantia da existência do representado. A oposição entre subjetivo e objetivo não existe desde o início. Ela somente se estabelece pelo fato de que o pensamento possui a capacidade de tornar de novo presente aquilo que fora percebido uma vez, por reprodução na representação, sem que o objeto tenha necessidade de ainda estar presente no fora. $\mathrm{O}$ fim imediato e inicial do exame da realidade não é o de encontrar na percepção real um objeto correspondente ao representado, mas de reencontrá-lo, convencer-se de que ainda existe. (Freud, 1925/1987, pp. 137-138)

O pensamento exerce então um trabalho ativo realizado por meio de pequenas quantidades de energia, tendo como meta o reencontro do objeto para se assegurar de sua existência, isto é, de sua realidade. É esse trabalho do pensamento que constitui o julgamento de existência.

André Green, que teorizou a partir de sua prática com pacientes fronteiriços, propôs uma cartografia das fronteiras/limites do aparelho psíquico. Há uma fronteira vertical, que separa o bom (o dentro) do mau (o fora); essa separação ocorre convenientemente à separação do sim (dentro) e do não (fora). Há também uma fronteira horizontal, que separa no espaço de dentro o agradável e 
o desagradável, o prazer e o desprazer. As duas fronteiras reunidas vão criar a separação entre a realidade interna, de um lado, e a realidade externa, do outro. A realidade interna comporta o consciente, os processos secundários, os afetos, as representações de prazer e desprazer e o recalcado inconsciente.

Bion, no artigo de 1957 "Diferenciação da parte psicótica e da parte não psicótica da personalidade”, tenta pôr em perspectiva às ideias de Freud relativas ao aparelho psíquico. Bion dá importância aos processos de pensamento, o que, para Green, é interessante por introduzir a dimensão intrapsíquica, contrabalançando a importância dada por Klein às relações de objeto e à identificação projetiva. Bion traz também a questão de um duplo ódio: o ódio da tomada de consciência da realidade interna e o ódio da realidade externa. No ódio da realidade interna, Bion, que trabalhou com pacientes graves, descreve também o que chamou de ataque contra os pensamentos. Green dialoga com as ideias de Bion e salienta a concepção da relação continente/conteúdo. É nesse ponto que o conceito de limite aparece para Green. A fim de estruturar essa oposição entre continente e conteúdo, o estabelecimento de um limite dentro/fora é uma condição básica necessária. Já com Winnicott aparece a ideia de um espaço intermediário, construído na relação entre a criança e o objeto externo, o qual é fundamental para começarmos a chegar a uma zona de fronteira, a um conceito de limite.

No trabalho analítico com pacientes da clínica atual é essencial o papel da contratransferência do analista como guia para a investigação desses psiquismos. Alguns autores chegam a dizer que nesses casos é preciso que o analista empreste seu inconsciente e seu pré-consciente ao paciente, como se o trabalho de representação do analisando necessitasse do inconsciente do outro para poder se efetuar. É por isso que nesses casos o analista deve estar muito atento a seus sonhos, alucinações, sensações corporais, dentro e fora das sessões. Esse conjunto de aspectos que se produzem na vivência do analista tem um movimento, uma respiração, no decorrer de cada sessão. Também é importante a noção de uma distância psíquica a ser mantida, a qual é necessária para evitar seja uma vivência de invasão, seja uma vivência de abandono.

Essas patologias atuais, nas quais encontramos dificuldades de representação por parte do paciente, demandam um lugar privilegiado para o analista, de modo que este possa agir tanto contra o desligamento quanto na 
construção dos traços mnêmicos que não tiveram representação de palavra. Neste ponto, vale lembrar a concepção do enquadre interno do analista (Green), fundamentado na experiência de sua análise pessoal, que lhe permite colocar em jogo sua capacidade de ligação por meio de sua capacidade sonhadora (rêverie), a qual vai trabalhar nessa zona de fronteira.

\section{O conceito de limite/fronteira: a recusa da realidade e a clivagem}

Para Freud o nascimento do objeto não vem como resultado de uma separação progressiva do corpo da criança. No artigo "A negação" (1925/1987) ele sustenta a existência de uma separação que ocorreria desde o começo, a separação dentro/fora.

A concepção freudiana de um Ego realidade originária pressupõe a possibilidade da distinção entre dentro e fora. A mudança no julgamento sobre a existência do objeto não seria lenta e progressiva, mas sim uma decisão súbita da função do julgamento. Assim, podemos dizer que o bebê "descobre" o objeto externo, o qual já era investido antes de ser percebido (Lebovici), a partir de sua função de julgamento de existência, que estará madura em torno do oitavo mês, época da primeira grande revolução psíquica após o nascimento: a descoberta do outro. René Diatkine (comunicação pessoal, 1991) considerava que essa crise do oitavo mês se deve ao fato de que o bebê descobre que a mãe existe independentemente dele e isso gera dor psíquica. Essa dor será o motor dos processos de satisfação alucinatória e de criação da realidade psíquica.

A função de julgamento de existência se contrapõe à reconstrução da experiência passada para o estabelecimento da prova de realidade. O modo figurativo de comunicação teria uma função transicional entre os afetos, que não são representáveis de forma figurativa, e o pensamento.

No texto "O fetichismo" (1927/2014a), Freud inaugura um novo desenvolvimento metapsicológico que se caracteriza pela aparição de uma defesa-chave: a Verleugnung ou recusa da realidade, a qual é fundamental para a constituição da clivagem do Ego. Penso que podemos dar uma dimensão mais ampla à recusa da realidade, uma vez que ela pode ser entendida como descrevendo um modo de estruturação psíquica que vai além da perversão fetichista. A partir da recusa da realidade nós podemos conceber um aparelho 
psíquico com um Ego clivado. A recusa da realidade é um procedimento muito antigo e profundo que se organiza por ocasião de um traumatismo. Ela promove a recusa categórica de uma realidade que aparece como intolerável e cuja existência mesma deve ser rejeitada. A prova de realidade é colocada fora do circuito e as fantasias de desejo são reconhecidas como uma realidade melhor. Em "Complemento metapsicológico à teoria dos sonhos", Freud afirma sobre a recusa da realidade: temos "um espetáculo interessante de uma desunião do $\mathrm{Eu}$ em relação a um de seus órgãos" (1917/2010a, p. 167). A recusa se põe contra a própria percepção da realidade. A partir de 1923, Freud considera a castração o objeto de eleição principal da Verleugnung. Mais à frente, nos anos 1937-1938, com os textos "Construções em análise" (1937/2018b) e "A clivagem do Ego dentro dos processos de defesa" (1938/2018a), a compreensão da recusa da realidade progride. Freud mostra que a aceitação e a recusa da realidade da castração são mantidas simultaneamente, o que leva a um esgarçamento no Ego, uma clivagem do Ego, que vai crescer e talvez ficar incurável. A recusa torna evidente a não existência de algo intolerável, a começar pelo conflito. $\mathrm{Na}$ conferência 31 Freud diz:

O Eu pode tomar a si mesmo por objeto, tratar a si mesmo como a outros objetos, observar-se, criticar-se e fazer sabe Deus mais o que consigo mesmo. Nisso uma parte do Eu contrapõe-se ao resto. Portanto, o Eu é divisível, ele se divide durante várias de suas funções, ao menos provisoriamente. Suas partes podem unir-se novamente depois. (1933/201ob, p. 194)

Num interessante artigo sobre as patologias atuais, Marucco (2006) defende a ideia de que se, por um lado, na história do declínio do Édipo, o sujeito, diante da ameaça de castração, vai recalcar o complexo de Édipo criando o inconsciente recalcado, por outro lado, outra parte do Ego vai recusar a realidade da castração. Essa última parte do Ego vai "instaurar um inconsciente não recalcado, um inconsciente que é o produto da recusa da realidade, com suas vias de retorno específicas" (Marucco, 2006, p. 845). O mesmo autor descreve o que chamou de fetiche virtual, que ocorre quando a transmutação de valor se desloca do pênis materno para um objeto que não é concreto, um objeto criado pelo desejo, como o brilho do nariz no paciente descrito por Freud.

Essa outra coisa, que não pode ser apreendida, imaterial, é uma condição para garantir a sobrevivência da pulsão, porque a castração é contornada pelo 
deslocamento em direção a um objeto que possui alguma coisa do objeto primário, incestuoso, sem, no entanto, ser ele. (Marucco, 2006, p. 846)

Dessa maneira o fetiche virtual seria uma condição da escolha amorosa e da criatividade. A falha na construção desse fetiche virtual, que garante algo da pulsão edípica, levaria à perda da capacidade de amar, descrita, por exemplo, nas normopatias.

A clivagem restaura um limite, permite a comunicação a partir dos afetos e dos processos de pensamento, verbalmente incomunicáveis. Sinto-me afinado com Green, que propôs dar ao limite um estatuto conceitual, o que não havia feito Freud. Para tanto, retomou o conceito mais fundamental da teoria psicanalítica - a pulsão. Essa fora definida por Freud (1938/2018a) como um conceito-limite, situado no limite dos domínios do somático e do psíquico. Desse conceito-limite, Green propõe extrair um conceito do limite. Partindo então dessa aproximação com a pulsão vai se delinear uma definição do limite:

é necessário então considerarmos o limite como uma fronteira móvel e flutuante [grifo meu], tanto na normalidade quanto na patologia. O limite é talvez o conceito mais fundamental da psicanálise moderna. Não devemos formulá-lo em termos de representação figurada, mas sim em termos de processos de transformação de energia e de simbolização (força e significação). (Green, 1976/1990a, pp. 125-126)

Os dois lados extremos da pulsão, que são sua origem somática e sua meta (o agir), delimitam o campo psíquico inconsciente. Freud propõe que a tarefa do campo psíquico estaria ligada à redução da tensão de desprazer, ou do excesso de tensão. Já Green propõe que a função fundamental do campo psíquico seria a representação, o representar, no sentido mais amplo possível. Trata-se da existência de um modo plural e heterogêneo de representação, contendo representantes-representações e representações de palavras, de afetos, gestos, atos e estados corporais. Esse campo psíquico sofre duas pressões: de um lado, as moções pulsionais que querem a ação específica; de outro, o impacto do objeto por meio de sua representação.

Considerando a clivagem de maneira ampla, podemos dizer que ela ocorre toda vez que há a tentativa de separar o bom do mau, o prazer do desprazer; a obrigação de distinguir entre si mesmo e o objeto, o dentro e o fora, o soma e a psique, a fantasia e a realidade. 
A clivagem está relacionada à pulsão da morte, pois esta é uma força que desliga, separa. Sua função essencial é disjuntiva e traz a necessidade de lembrarmos seu termo complementar, a confusão, frequentemente presente nas fronteiras móveis da clínica atual.

A atitude do objeto é considerada fundamental para o desenvolvimento da clivagem. Há duas possibilidades extremas dessa atitude: ausência de fusão por parte da mãe - a criança encontra então um seio branco (Green, 1976/1990a) ou excesso de fusão com a mãe, a qual é incapaz de renunciar ao prazer redescoberto com a gravidez e o aleitamento.

Como resultado da clivagem podemos afirmar que alguma coisa é excluída, rejeitada, recusada. Essa coisa é inelaborável e impensável. Além disso, os elementos clivados retornariam com uma qualidade persecutória intrusiva, caracterizando o par de angústia predominante na clínica de pacientes fronteiriços: angústia de intrusão e angústia de abandono.

A intrusão é descrita como uma violência imposta, a partir do interior, pelo objeto interno que interdita o pensamento. Daí a preocupação central desses pacientes em manter a identidade e a autonomia do próprio pensamento. Esse aspecto coloca inúmeras dificuldades no manejo e uso das interpretações do analista. O paciente tende a se entregar a uma luta vital desenfreada pela manutenção da identidade diante de um objeto que é sempre intrusivo e ameaçador. Alguns pacientes se retiram, isolando-se em seu próprio pensamento.

A clivagem aparece de diversas maneiras - por exemplo, entre soma e psique, ou entre sensações corporais e afetos, ou ainda em formas mais sutis, como o processo de isolação que provoca uma disjunção entre afetos e representações (pensamento). Mesmo a atividade motora pode estar clivada do psíquico.

Um primeiro limite que se estabelece é entre soma e psique. O soma clivado retorna fazendo intrusão no aparelho psíquico, sob a forma de sintomas psicossomáticos ou de hipocondria. Green (1976/1990a) introduz nesses casos a ideia de uma agressividade neutralizada, a qual estaria próxima de uma destrutividade pura, no sentido que Freud fala de uma pura cultura da pulsão de morte. 
Um segundo limite seria criado pela clivagem entre realidade externa e realidade psíquica. Na passagem ao ato (atuação) há uma ausência de simbolização. Ela é uma ação expulsiva, evacuadora e aparentemente desprovida de sentido. Mesmo que a passagem ao ato possa obter uma significação simbólica para o analista, isso não ocorre com o paciente, para quem ela é simples descarga. Freud chamou de ação específica a ação que tem o poder de transformar uma situação de impotência em uma experiência que traga satisfação. A passagem ao ato, o agir, é o contrário da ação específica, pois sua função principal é a descarga da tensão para se proteger. Há na passagem ao ato uma precipitação na ação, criando um curto-circuito da realidade psíquica.

No recalque o que retorna é simbolizado, estando ligado a representações, afetos e derivados do Id. Fato essencial aqui: a energia psíquica está ligada. Já na clivagem os elementos ligados foram atacados, destruídos. Somente um intenso trabalho da construção imaginativa do analista pode, às vezes, conseguir reconstruir o que foram essas ligações atacadas e destruídas.

$\mathrm{O}$ retorno do recalcado se relaciona à angústia, enquanto o retorno do clivado dá origem a sentimentos difíceis de serem colocados em palavras, que se aproximam do desamparo (Hilflosigkeit, de Freud), da aniquilação (M. Klein), do terror sem nome (Bion), da desintegração ou do suplício (Winnicott).

A clivagem dentro/fora constitui um envelope que traça os contornos do Ego, embora não funcione como uma barreira de proteção. Nesses pacientes o Ego apresenta uma variabilidade dos limites, a qual não é vivenciada como um recurso positivo. Trata-se de um Ego rígido e sem coesão. Dentro do aparelho psíquico a clivagem pode criar núcleos isolados, mais ou menos estruturados, que ficam totalmente sem comunicação entre eles. A imagem de um arquipélago, trazida por Michel de M’Uzan (citado por Green, A. 1976, p.133), parece figurar o resultado dessa clivagem interna. Como as ilhas não se relacionam entre si, isso provoca a impressão de um conjunto contraditório de relações, de um Ego sem coesão nem coerência. Assim, nesses casos encontramos fantasias, pensamentos e afetos contraditórios convivendo simultaneamente. Então podemos dizer que o pensamento é atingido. Essa ausência de coesão descrita para o Ego leva a sentimentos de desinteresse, desligamento, falta de vitalidade, impossibilidade de se sentir existindo, impressão de futilidade em tudo, etc. 
Outro mecanismo de base que opera em pacientes não neuróticos é o que certos autores chamam de depressão primária. Green a define como um "desinvestimento radical, que cria estados de branco do pensamento sem nenhum componente afetivo, como dor ou sofrimento" (1976/1990a, p. 134). O paciente mostra uma impossibilidade em representar e uma baixa do investimento do seu próprio psiquismo. Não há interesse nem prazer algum por seu funcionamento psíquico.

Consideremos o papel do agir num funcionamento psíquico do tipo fronteiriço. Esse funcionamento no agir não se limita às ações, pois esse agir pode atingir sonhos, fantasias, produtos da linguagem, sob um modo expulsivo. Por exemplo, um paciente que mantém um discurso num fluxo contínuo, um discurso cuja função é de descarga, de evacuação. Como consequência de tais aspectos, esses pacientes não conseguem colocar em suspensão o discurso, para assim associar livremente nas sessões.

Lacan, citado por Green (1976, p.139), considerou que o conceito de ausência não comportaria nem perda nem morte. Seria um estado intermediário, no meio do caminho entre a presença e a perda. A ausência é fruto de um árduo trabalho psíquico:

é preciso um esforço considerável para tolerar a ausência, diferenciá-la da perda e dar ao mundo da representação seu pleno papel: imaginação e pensamento. Somente a ausência do objeto pode estimular a imaginação e o pensamento, em outras palavras, a criatividade e a vitalidade psíquicas. (Green, 1976/1990a, p. 139)

O enquadre analítico é submetido a dura prova com pacientes que apresentam problemas de pensamento. Esses casos têm muita dificuldade com a situação criada pelo enquadre analítico. Os casos fronteiriços tendem a atacar frequentemente o enquadre.

No artigo "O silêncio do psicanalista" (1979/199ob), Green mostra que o enquadre analítico veio do modelo do sonho e visa a produção de pensamentos não pensados. A analogia feita aqui é com o trabalho do sonho. No entanto, o trabalho do sonho não está garantido por si só; ele vai depender do tipo de organização psíquica que abordamos. $\mathrm{O}$ enquadre analítico modifica a economia dos limites do paciente. As variações do enquadre analítico, muitas vezes necessárias com a clínica atual, encontram seu fundamento no conceito de 
enquadre interno do analista, que é o garantidor do método analítico. O enquadre é a condição do objeto analítico, um objeto terceiro produzido pela comunicação de cada par analítico singular. A escuta no enquadre analítico tem uma significação polissêmica: escuta da unidade (narcisismo), escuta da dupla (mãebebê), escuta do intermediário (ilusão transicional) e escuta da triangulação (lei paterna e interdição do incesto). As modificações no enquadre devem buscar estabelecer as melhores condições para o funcionamento representativo.

A constituição do enquadre interno do analista representa o núcleo dialógico (intersubjetivo) da análise, funcionando como uma matriz representativa pré-consciente. A contratransferência, nessa visão, fica integrada na concepção mais ampla e mais complexa do trabalho psíquico do analista e torna-se parte do enquadre interno dele. Como consequência disso a posição do analista é múltipla e variável. Nem pai edípico nem mãe continente, o analista deve jogar, brincar, diante dos cenários que se desenrolam no campo analítico. Há aqui a ideia da construção do ambiente psíquico e do pré-consciente do analista como um espaço transicional; no lugar do sonho, o jogo, o brincar.

\section{Referências}

Bion, W. R. (1957). Differentiation of the psychotic from the non-psychotic personalities. The International Journal of Psychoanalysis, 38, 266-275.

Freud, S. (1987). La négation. In S. Freud, Résultats, idées, problèmes (A. Bourguignon \& P. Cotet, Trads., Vol. 2, pp. 135-139). PUF. (Trabalho original publicado em 1925)

Freud, S. (2010a). Complemento metapsicológico à teoria dos sonhos. In S. Freud, Obras completas (P. C. Souza, Trad., Vol. 12, pp. 151-169). Companhia das Letras. (Trabalho original publicado em 1917)

Freud, S. (2010b). A dissecção da personalidade psíquica. In S. Freud, Obras completas (P. C. Souza, Trad., Vol. 18, pp. 192-223). Companhia das Letras. (Trabalho original publicado em 1933)

Freud, S. (2011a). O Eu e o Id. In S. Freud, Obras completas (P. C. Souza, Trad., Vol. 16, pp. 13-74). Companhia das Letras. (Trabalho original publicado em 1923) 
Freud, S. (2011b). Neurose e psicose. In S. Freud, Obras completas (P. C. Souza, Trad., Vol. 16, pp. 176-183). Companhia das Letras. (Trabalho original publicado em 1924)

Freud, S. (2014a). O fetichismo. In S. Freud, Obras completas (P. C. Souza, Trad., Vol. 17, pp. 302-310). Companhia das Letras. (Trabalho original publicado em 1927)

Freud, S. (2014b). Psicanálise. In S. Freud, Obras completas (P. C. Souza, Trad., Vol. 17, pp. 311-321). Companhia das Letras. (Trabalho original publicado em 1926)

Freud, S. (2018a). A cisão do Eu no processo de defesa. In S. Freud, Obras completas (P. C. Souza, Trad., Vol. 19, pp. 345-350). Companhia das Letras. (Trabalho original publicado em 1938)

Freud, S. (2018b). Construções na análise. In S. Freud, Obras completas (P. C. Souza, Trad., Vol. 19, pp. 327-344). Companhia das Letras. (Trabalho original publicado em 1937)

Green, A. (1990a). Le concept de limite. In A. Green, La folie privée (pp. 103-140). Gallimard. (Trabalho original publicado em 1976)

Green, A. (199ob). Le silence du psychanalyste. In A. Green, La folie privée (pp. 317-346). Gallimard. (Trabalho original publicado em 1979)

Marucco, N. C. (2006). Débats théoriques sur la pratique analytique actuelle: réflexions métapsychologiques, cliniques et techniques. In A. Green (Dir.), Les voies nouvelles de la thérapeutique psychanalytique: le dedans et le dehors (pp. 827-859). PUF. 